\title{
Understanding the Palm Oil Utilization Preference: A Literature Review and Preference Measurement
}

\author{
Lusi Zafriana $^{1}$ and Zaenal Fanani ${ }^{1}$
}

\begin{abstract}
Energy supply security has become the world's issue this past decades. World's energy demand keep growing yet supply remains stable. Numerous renewable energy sources are developed to fulfil this energy supply gap. This issue is also being a concern in Indonesia. Palm oil is considered as one of the renewable energy because of its production flexibility. Palm oil could be processed into cooking oil and fuel energy such as biodiesel. Objective of this present study is to understand the palm oil utilization preference either as the cooking oil or biodiesel. Literature review is conducted to explore variables that is being considered as preference variable. This present study conducted review in several literature that were published ranged from 2010 to 2018. Three variables were considered as a result of literature review. The first variable is sustainability aspect which represent life cycle of the processed product. The second variable is policy which could influence the industry's stakeholder to conduct a utilization decision. The last variable is emission that is being produced by the processed product. This present study also conducted preference measurement in order to measure the preference of palm oil utilization either as he cooking oil or biodiesel. As the result, a research map is proposed for the future research direction.
\end{abstract}

Keywords-Palm Oil, Cooking Oil, Biodiesel, Preference Measurement.

\section{INTRODUCTION}

In recent years, the world's energy supply has become a problem in various countries[1]. The world's energy needs are increasing year by year but the energy supply is not able to meet these energy needs. World energy security is threatened, moreover the consumption of fuel derived from fossils has begun to be abandoned[1]. This situation is referred to as the world energy crisis which requires a solution as a new energy source for the world. In the last two decades several new energy sources have been developed including natural gas, water, palm oil, and biofuels. In addition to being used as a supply of renewable energy sources, some of these commodities are used as means of the state as a solution to the decline in imports of crude oil and fuel, as well as the addition of jobs[2], [3]. In some countries, such as Indonesia and Malaysia, palm oil is one of the largest promising export commodities. The consumption of world palm oil from year to year has increased because of its function which can be used as many things and constituents of fuel[4].

\footnotetext{
${ }^{1}$ Lucky Adhitiya and Rifelly Dewi Astuti are with Magister of Management, Universitas Indonesia, Jakarta, 10430. Email: luckyadhitiya16@gmai.com; rifelly.dewi@gmail.com.
}

The trend in the consumption of palm oil as a food ingredient or as a constituent of fuel has its own aspects in various parts of the world. One issue that has developed in recent years that can affect the adoption of palm oil as a food ingredient or as a biodiesel ingredient is the issue of sustainability of the palm oil commodity itself[5]. The sustainability perspective explains the supply of oil palm which is related to the quantity of oil palm and the life cycle of the oil palm itself[6], [7]. Other considered aspects related to the policies made by a country to influence the use of palm oil as cooking oil and as a base for biodiesel are policies that apply to the industry's stakeholder in a country[8]-[10]. Usage preferences are also sometimes influenced by other factors such as emissions, where currently the community and industry have begun to be aware of the effects of emissions on the environment[11] [13]. So, in this present study we will conduct a literature review of several articles by focusing on factors such as sustainability issues, government policies, and emissions that can affect the preference for using palm oil as food or as diesel.

\section{LITERATURE REVIEW}

\section{A. Biodiesel}

Biodiesel is a fuel that is usually used for compression machines produced from biological resources such as fatty oils or vegetable oils or animal fats. Biodiesel is a fuel that can be produced with basic ingredients from raw vegetable oil, it can also be produced from used vegetable oil[14]. Composite materials for biodiesel are usually adjusted to the resources found in a country. For example, Indonesia and Malaysia that produce a lot of oil palm trees, so many biodiesel production is made from palm oil. While in several other countries many are composed of sunflower oil, rapseed oil, and jathropa oil.

\section{B. Cooking Oil}

\section{1) Multi Criteria Decision Making Methods}

Decision making is a typical of selecting an optimum alternative among several alternatives that could be presented in a problem[15]. Sometimes, when conducting a decision, a decision maker has to consider several factors. This condition lead to a condition when multi criteria decision making occur[15]. Multi Criteria Decision Making (MCDM) is a method that could be applied in an individual level and in an integrated level[16]. The key point of MCDM is to rank several alternatives and to select the 
most optimal solution based on a certain approach and existing decision information by considering several criteria.

2) Analytic Hierarchy Process (AHP)

Analytic Hierarchy Process (AHP) is one of MCDM approaches that has has been applied as a decision making aproach this past decades. This approach able to involve qualitative data as a consideration[17]. It means that this approach involves both qualitative and quantitative data. AHP is using a reciprocal decision matrix obtained by pairwise comparisons so that the information is given in a linguistic form[17]. AHP could be applied when a decision maker has to deal with complex, unstructured, and multiple-attribute decisions[18]. AHP has been widely applied in several fields of industry's decision[18]. AHP involves three basic steps: the first step is to describe a complex decision case as a hierarchy, the following step will be prioritizing procedure; and the third step is to calculate the results. As the first step of AHP, describing a complex decision case is an important step since this step require a disintegrating the unstructured decision into several components and arranging them in a hierarchical level[18]. AHP also involves three principles such as decomposition, compartive judgements, and synthesis of priorities [19]. The principle of decomposition leads to the construction of hierarchical network to present a decision case, with the importance to represent the overall goals and the lower levels representing criteria, sub-criteria, and alternatives[19].

3) Weighted Scoring Method (WSM)

Weighted Scoring Method (WSM) is one of several approaches that could be applied to conduct a decision. This approach usually functioned to evaluate and select an optimal decision[20]. To conduct this approach, several alternatives need to be listed and considered with their deterministic criteria. A decision matrix will be characterizing these alternatives[19]. A scoring will be performed to measure how good an alternatives on a criterion. The higher the score is, the better the alternatives[20]. This approach is relatively simple because it only involves scoring method.

\section{METHODOLOGY}

The methodology in this paper consists of two stages, first: determining the criteria for analyzing the use preferences of processed palm oil into cooking oil and biodiesel. The method used is the study of literature. The literature study was carried out in fifteen studies from the range of 2010 to 2018. The expected output from the first stage is aspects that need to be considered in the use preferences of processed palm oil. In addition, it is also hoped that the direction of further research in the form of research maps from some of the literature reviewed. The following step is to select a method that is able to provide an assessment of the criteria for each alternative biofuel in predicting the potential for development and utilization. The stages of research is illustrated in Figure 2.

Tahap 1. Penentuan kriteria penilaian analisis ekonomi biofuel

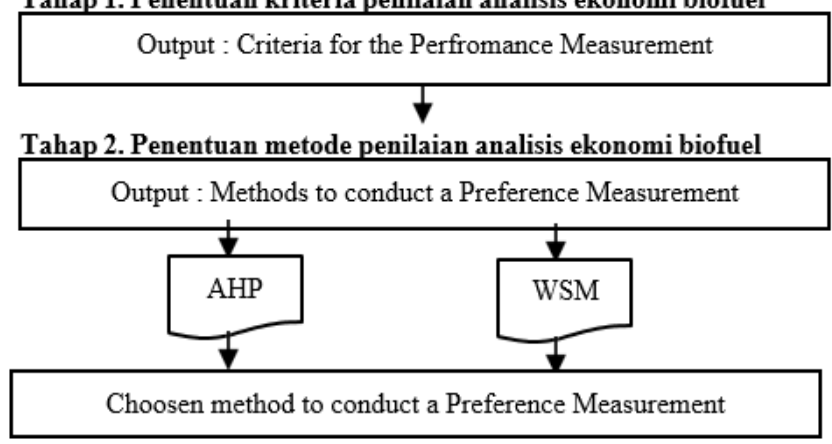

Figure 2. Research Methodology

\section{RESULTS AND DiSCUSSION}

\section{A. Preference Criteria of Palm Oil Utilization: Cooking Oil vs Biodiesel}

In this study based on literature obtained from the Google Scholar search engine. Research on the economic analysis of biofuel development is limited. This study uses literature from 2009 to 2018. Several studies mention economic or socio economic impacts. In this study classifying two economic impacts, there are economic impacts and socio-economic impacts. This study divides 4 categories in looking at the economic analysis of biofuel development, namely production costs, selling prices, economic impacts, and socio- economic impacts.

1) Sustainability

a. Palm Oil's Sustainability as Cooking Oil

In India, consumer demand for palm oil as food is actually not too high. Even the designation of palm oil in India is "the cooking oil of those who are less able" This shows that the use of palm oil as cooking oil is still in great demand in India [21]. India is one of the countries with the largest population in the world, but also still holds the status of a developing country. The status of India as a developing country indicates that the Indian population is relatively price-sensitive. The issue of sustainability for palm oil as food can only be heard by certain groups of highly educated and middle-class people. This also indicates that the understanding of most Indians is less educated regarding the sustainability of palm oil. So, it makes sense if the demand for palm oil as cooking oil in India is relatively high even $90 \%$ of palm oil imported by India is used as cooking oil. Interestingly, Schleifer's research revealed an anomaly in which although the state of India which is still dominated by lower middle class people who still feel less education about the sustainability of palm oil as cooking oil is expected to experience a decline in demand for palm oil as cooking oil. According to Schleifer[21], the Indian market is a fragmented market form where almost the entire value chain is with palm oil. The fragment here means that although interest in palm oil 
as cooking oil is relatively high, there is also a share of this interest in branded palm cooking oil with unbranded palm cooking oil. Other considerations that show Indian people's preference for using palm oil as cooking oil. For the sustainability variable, it can be motivated by the existence of social movement pressure, local program capacity, support of the host government and international support.

Unlike the case with China, people's understanding of renewable energy products has increased. Although there are many who know about renewable energy products, they still don't understand how they relate to palm oil. Interestingly, among various products that have been certified, palm oil which is processed into cooking oil is considered less healthy because it contains saturated fat. As it turns out, manufacturers in the food industry in China are also trying to overcome the negative preferences of Chinese people for palm oil processed products by changing the phrase that shows the identity of palm oil with 'vegetable oil'. However, still because of the negative image of Palm Oil in the eyes of Chinese consumers, they tend to stay away from products containing palm oil so that palm oil is less well known among Chinese people.

Slightly different when using global glasses to see the development of the use of palm oil as one of the ingredients of cooking oil. Shankar[22] states that the use of palm oil as cooking oil shows a relatively large proportion in the vegetable oil market and even controls up to $33 \%$ of the consumption of vegetable oil in the world. According to him, the increase in the use of palm oil is more significantly used as food rather than used as fuel such as biofuel even though biofuel also contributes to increasing the amount of palm oil use. Food is intended here not only in the context of cooking oil, but also as an ingredient from instant noodles to coffee bleach. But there are considerations such as those that occur in China about health issues in palm oil because the saturated oil content is much higher than other vegetable oils that have the potential to cause LDL cholesterol.

Selling Prices

The selling price of biofuels is influenced by production costs and availability of raw materials. The selling price determines the purchase decision of biofuels by the customer. Demirbas found that price competitiveness, affordability, and reliability compared to fossil fuels are important factors for the spread of biofuel production systems[7]. Indonesia's biofuel market is dependent on government subsidies because the price of biofuels is higher than crude oil[6].

It is known that the raw material used for bioethanol is sugar cane. Increasing the price of sugar cane as a raw material for food and raw materials for biofuels makes sugar cane prices increase. This will increase production costs, and the selling price of bioethanol will be expensive. While if it involves a mixture of bioethanol and fossil oil, the price index of the bioethanol market with gasoline is pertalite which has a high price difference. b. Palm Oil's Sustainability as Biodiesel

A country's policy can also influence the consumption preferences of palm oil as a supporting material for biodiesel. One example is the policy in Thailand to encourage the use of palm oil as a supporting material for biodiesel as discussed in Nupueng et al., [10]. To supply feedstock for biodiesel, the Thai government made arrangements for a minimum of 200,000 tons of CPO reserves. Arrangements regarding palm oil standards for biodiesel are regulated in the Guidelines for the Development of Biodiesel Standards in the APEC Region (Thailand Institute of Scientific and Technological Research, 2009). To meet the standard palm oil regulation for biodiesel, the Thai government allocates a monthly biodiesel quota to each of the oil palm plantations based on existing demand. The main objective of this government regulation is to safeguard the domestic palm oil sector. The Thai government is trying to promote, support and intervene in the biodiesel industry because it is considered to increase the income of oil palm farmers while at the same time being able to control the use of palm oil as cooking oil. In fact, under normal conditions, it is assessed that biodiesel production is an efficient domestic energy source to reduce fuel imports.

Looking back, arrangements related to biodiesel have also been implemented, one of which is in the Kyoto Protocol which is an international environmental organization. Malaysia, as one of the palm oil supply countries, also supports output from the Kyoto Protocol to achieve environmental stabilization. In October 2008, Malaysia mandated that there would be $5 \%$ of biodiesel to be used in 2009 and implemented the mandate on a large scale in 2010 in the industry and transportation sector[23]. However, this had experienced difficulties because the form of policy made was considered unclear and lacking in direction from the government so that biodiesel had experienced a lack of attractiveness in the transportation industry.

2) Policy for Palm Oil

a. Policy for Palm Oil as Cooking Oil

Shankar's research also discusses how regulations in a region can influence consumer preferences in choosing to use palm oil as food. For example, considering that food containing palm oil contains a lot of saturated fat, Denmark imposes a higher tax on food products that contain high saturated fat[22]. Even products that can replace the use of palm oil will be subsidized. Whereas in Thailand, because of considering the economic conditions of the people, palm oil is permitted to be used for those with low income. Whereas other vegetable oils can only be purchased by those who are well off. Similar conditions are experienced by Indonesia as well as developing countries such as the Gaskell [24] study. In the 1980s, the tax structure continued to support domestic palm oil consumption. Palm oil is subject to an export tax of $10 \%$, there is also a quota policy that can encourage consumption of domestic palm 
oil. Both of these studies indicate that policy can affect a country's domestic consumption.

\section{b. Policy for Palm Oil as Biodiesel}

A country's policy can also influence the consumption preferences of palm oil as a supporting material for biodiesel. One example is the policy in Thailand to encourage the use of palm oil as a supporting material for biodiesel as discussed in[10]. To supply feedstock for biodiesel, the Thai government made arrangements for a minimum of 200,000 tons of CPO reserves. Arrangements regarding palm oil standards for biodiesel are regulated in the Guidelines for the Development of Biodiesel Standards in the APEC Region (Thailand Institute of Scientific and Technological Research, 2009). To meet the standard palm oil regulation for biodiesel, the Thai government allocates a monthly biodiesel quota to each of the oil palm plantations based on existing demand. The main objective of this government regulation is to safeguard the domestic palm oil sector. The Thai government is trying to promote, support and intervene in the biodiesel industry because it is considered to increase the income of oil palm farmers while at the same time being able to control the use of palm oil as cooking oil. In fact, under normal conditions, it is assessed that biodiesel production is an efficient domestic energy source to reduce fuel imports.

Looking back, arrangements related to biodiesel have also been implemented, one of which is in the Kyoto Protocol which is an international environmental organization. Malaysia, as one of the palm oil supply countries, also supports output from the Kyoto Protocol to achieve environmental stabilization. In October 2008, Malaysia mandated that there would be $5 \%$ of biodiesel to be used in 2009 and implemented the mandate on a large scale in 2010 in the industry and transportation sector[23]. However, this had experienced difficulties because the form of policy made was considered unclear and lacking in direction from the government so that biodiesel had experienced a lack of attractiveness in the transportation industry.

\section{3) Emissions of Palm Oil}

a. Emissions of Palm Oil as Cooking Oil

Palm oil which is used as cooking oil consists of a chemical mixture. This mixture is of concern to many parties because some of the composers of this mixture are considered carcinogenic and have many fatty acids. As in the Peng [13] study which aims to compare the composition of the aldehyde and the concentration in cooking oil with different forms of cooking oil, cooking method, and type of cooking.

De Souza, Pacca, De Ávila, \& Borges [25] analyzed life cycle emissions and the energy balance of palm oil biodiesel production in Brazil. Energy balance is found at 1: 5.37 by the researcher. This research can provide an overview of biodiesel sustainability factors, in terms of production efficiency and greenhouse gas emissions. The factors involved cover: 1 . Use of nitrogen fertilizer (increasing GHG emissions and reducing the NER ratio); and 2. Use of green manure (reducing GHG emissions and increasing NER ratios. Meanwhile, Rocha et al. (2014) uses the Live Cycle Assessment (LCA) in the Well-ToTank (WTT) perspective to evaluate and compare the impacts of major environmental life cycles and the energy balance of sugarcane ethanol, soybean biodiesel and palm oil biodiesel. From the evaluation conducted by the study, it was found that biofuel production systems with high agricultural output and frequent use of co-products in a life cycle showed the best environmental impact. that the choices of co-product allocation methods, transportation distances, and state- owned inventory databases have a significant impact on the environmental life cycle performance of biofuels.

b. Emissions of Palm Oil as Biodiesel

De Souza, Pacca, De Ávila, \& Borges [25] have also analyzed the emission impact. For comparison, other studies have energy balance ranges from 1: 3.40 (input energy versus output energy) to 1: 7.78. Life cycle emissions worth $1437 \mathrm{~kg} \mathrm{CO} 2 \mathrm{e} /$ ha were found by researchers, while other studies found a value of $2406 \mathrm{~kg}$ $\mathrm{CO} 2 \mathrm{e} / \mathrm{ha}$ in average. The difference in the results of this measurement lies in the difference in measurement of emissions and energy balance in the agricultural phase (including fertilizers, pesticides and irrigation). The biggest energy input in biodiesel production from palm oil is in the industrial stage (including oil extraction and transesterification). Sensitivity analysis was carried out in this study and it was found that nitrogen had a considerable influence on the ratio of NER (Net Energy Ratio) and GHG (Greenhouse Gas). However, the impact of nitrogen is also reduced due to the use of Pueraria phaseoloides (green fertilizer). Although the harvest was done manually, in this study it was found that the use of fuel oil contributed $18 \%$ of the total GHG emissions in the life cycle of palm oil biodiesel, covering its use in boiler engines. This is also supported by Kim's 2017 research stating that biodiesel with palm oil produces the lowest $\mathrm{CO}$ and NOx emissions compared to Soybean Oil, Rapeseed oil. However, palm oil $\mathrm{CO} 2$ gas production is higher than Rapseed oil and Jatropha oil. Several recent studies have looked for several feedstocks that can reduce emissions produced by palm oil biodiesel. One of them is the research of Radhakrishnan et al (2017) which seeks to determine the emission reduction that can occur if pentanol $(\mathrm{C} 5 \mathrm{H} 11 \mathrm{OH})$ is added to palm oil biodiesel. The addition of pentanol proved to be able to reduce $\mathrm{CO}$ emissions by $9.3 \%, \mathrm{HC}$ emissions by $3.8 \%$, and NOx emissions by $6.6 \%$, and smoke emissions by $2.7 \%$ when compared to pure palm oil. If observed, the world trend towards the use of palm oil until 2013 is still relatively low. The use of palm oil as biodiesel fuel is only $6 \%$ when compared to Canola (Rapeseed), soybean, animal fat, yellow grease, and sunflower[26]. 
The $1^{\text {st }}$ International Conference on Business and Management of Technology (IConBMT)

August 3rd 2019, Institut Teknologi Sepuluh Nopember, Surabaya, Indonesia

\section{B. Research Map}

Based on the results of the discussion in reviewing several papers related to processing palm oil preferences into food and becoming biodiesel compilers, a research map can be formulated for this study. The research map is grouped based on each variable that influences the preferences of each processed.

TABLE 3. RESEARCH MAP

\begin{tabular}{lccc}
\hline \hline \multirow{2}{*}{$\begin{array}{l}\text { Preferensi } \\
\text { Penggunaan Sawit }\end{array}$} & \multicolumn{3}{c}{$\begin{array}{c}\text { Preferensi Penggunaan Sawit berdasarkan } \\
\text { Beberapa Aspek }\end{array}$} \\
\cline { 2 - 4 } & Sustainability & Policy & Emissions \\
\hline $\begin{array}{l}\text { Sebagai Bahan } \\
\text { Pangan }\end{array}$ & {$[21],[22]$} & {$[22],[24]$} & {$[13]$} \\
Sebagai Biodiesel & {$[25],[27]$} & {$[10],[23],[28]$} & {$[11],[26]$,} \\
& & & {$[29]$} \\
$\begin{array}{l}\text { Sebagai Bahan } \\
\text { Pangan dan Biodiesel }\end{array}$ & {$[30]$} & & {$[31]$} \\
\hline \hline
\end{tabular}

With this research map, each study can complement each other. Based on the research map, there are two studies that can be used as references for reviewing the preference for using palm oil processed products as food in sustainability aspects, there are two studies, namely Schleifer \& Sun [21] and Shankar et al. [22]. Meanwhile, the preference for using palm oil processed products as food in the aspect of state policy is two studies, namely research Gaskell [24] and Shankar et al.[22]. Then, the preference for using palm oil processed products as food in the aspect of emissions issued, there is one study, namely research Peng et al. [13]. The preference for processed palm oil products is the composition of biodiesel which considers sustainability aspects, there are two studies, namely research De Souza et al. [25] and Rocha et al.[27]. Whereas, the preference for using palm oil processed products as a biodiesel constituent material that considers aspects of state policy is three studies, namely research Nupueng et al. [10], Yatim et al. [28], and Mekhilef[23]. Then, the preference for using palm oil processed products as a biodiesel constituent that considers the emission aspects there are three studies, namely research Radhakrishnan et al. [11], Kim et al. [26], and Wei et al. [29]. Whereas, the preference for using palm oil processed products as food and biodiesel is a study Bateman et al. [30] that considers sustainability and there is research Khatiwada et al. [31] that considers emissions aspects. With some of these studies, researchers can determine the direction of their research in future studies.

\section{Penentuan Metode Penilaian}

A comparison table is conducted to choose a relevant method for this present study. As shown in the Table 4, two methods is compared for several parameters.
TABEL 4.

PERBANDINGAN AHP DAN WSM[19].

\begin{tabular}{|c|c|c|}
\hline Parameters & AHP & WSM \\
\hline $\begin{array}{l}\text { Supports quantitative } \\
\text { parameters }\end{array}$ & Yes & Yes \\
\hline $\begin{array}{l}\text { When the number of } \\
\text { evaluated alternatives } \\
\text { increases }\end{array}$ & $\begin{array}{l}\text { Pairwise } \\
\text { comparisons also } \\
\text { increase and need to } \\
\text { be done to calculate } \\
\text { the final score }\end{array}$ & $\begin{array}{l}\text { The assessment of each } \\
\text { alternative with respect } \\
\text { to each evaluation } \\
\text { criteria must be carried } \\
\text { out before calculating } \\
\text { the final score. }\end{array}$ \\
\hline $\begin{array}{l}\text { When the number of } \\
\text { criteria changes }\end{array}$ & $\begin{array}{l}\text { Pairwise } \\
\text { comparisons also } \\
\text { increase and need to } \\
\text { be done to calculate } \\
\text { the final score. }\end{array}$ & $\begin{array}{l}\text { No extra effort is } \\
\text { needed to calculate the } \\
\text { final score. }\end{array}$ \\
\hline $\begin{array}{l}\text { Support to show how } \\
\text { well each soft } \\
\text { component meets the } \\
\text { requirements of the } \\
\text { component's users }\end{array}$ & No & No \\
\hline
\end{tabular}

In this present study, an assessment of WSM of the using preferences of processed palm oil as cooking oil and biodiesel is conducted. This is because WSM has a simpler calculation complexity compared to AHP. Added, according to the explanation of previous studies that the WSM and AHP have similarities in ranking results.

\section{Penilaian Preferensi Penggunaan Olahan Minyak Sawit}

WSM assessment is cconducted by giving weight and value to each alternative. Grading with a rating of 1 to 5 , with a value of 5 for the highest score. Giving criteria weights has a total of $100 \%$ in each alternative. Then the final calculation for each alternative is done to determine the highest value. The assessment and aggregate score for each alternative can be seen in Table 5 .

TABEL 5.

AGREGAT SCORE OF PALM OIL ALTERNATIVES USING WSM

\begin{tabular}{llrlr}
\hline \hline Alternative & Criteria & Weight & Rating & Score \\
\hline Cooking Oil & Sustainability & $30 \%$ & 3 & 0.9 \\
& Policy & $40 \%$ & 4 & 1.6 \\
& Emissions & $30 \%$ & 3 & 0.9 \\
& Total Score & $100 \%$ & & $\mathbf{3 . 4}$ \\
\hline Biodiesel & Sustainability & $30 \%$ & 4 & 1.2 \\
& Policy & $40 \%$ & 5 & 2 \\
& Emissions & $30 \%$ & 3 & 0.9 \\
& Total Score & $100 \%$ & & $\mathbf{4 . 1}$ \\
\hline \hline
\end{tabular}


Based on the table, the preference for using palm oil processed is more likely to be used as Biodiesel. Significant variables that influence this preference are related to the policies applied by the state.

\section{CONCLUSION}

Palm oil can be used for various preparations. Palm oil is often processed as food such as cooking oil. Can also be processed as a constituent of fuel, one of which is a constituent of biodiesel. The preference for the use of processed palm oil is different. In this study, there are three variables considered including sustainability aspects, policy aspects in a country, and aspects of emissions produced from each processing. Using the WSM method, measurements have been made on the use of processed palm oil. From a sustainability aspect, the preference for using palm oil as a biodiesel constituent is superior to cooking oil with a longer life- cycle of palm oil as biodiesel. If observed from the aspect of state policy, several countries in the world are actively pushing for the use of biodiesel, so that the preference for using processed palm oil as biodiesel is superior to cooking oil. Based on other aspects, namely emissions, processed palm oil as cooking oil is superior to biodiesel because the output of emissions produced by cooking oil is lower than from biodiesel. Further research, can carry out further analysis related to other factors that can influence the preference for using palm oil processed.

\section{REFERENCES}

[1] M. Asif and T. Muneer, "Energy supply, its demand and security issues for developed and emerging economies," Renew. Sustain. Energy Rev., vol. 11, no. 7, pp. 1388-1413, Sep. 2007.

[2] A. Kumar et al., "A review of multi criteria decision making (MCDM) towards sustainable renewable energy development," Renew. Sustain. Energy Rev., vol. 69, pp. 596-609, Mar. 2017.

[3] H. Dai, X. Xie, Y. Xie, J. Liu, and T. Masui, "Green growth: The economic impacts of large-scale renewable energy development in China," Appl. Energy, vol. 162, pp. 435-449, Jan. 2016.

[4] Y. Sun, N. Neelakantan, Y. Wu, R. Lote-Oke, A. Pan, and R. M. van Dam, "Palm oil consumption Increases LDL cholesterol compared with vegetable oils low in saturated fat in a metaanalysis of clinical trials," J. Nutr., vol. 145, no. 7, pp. 15491558, Jul. 2015

[5] J. Janaun and N. Ellis, "Perspectives on biodiesel as a sustainable fuel," Renew. Sustain. Energy Rev., vol. 14, no. 4, pp. 1312-1320, May 2010.

[6] K. F. Yee, K. T. Tan, A. Z. Abdullah, and K. T. Lee, "Life cycle assessment of palm biodiesel: Revealing facts and benefits for sustainability," Appl. Energy, vol. 86, pp. S189-S196, Nov. 2009.

[7] Y. Manik, J. Leahy, and A. Halog, "Social life cycle assessment of palm oil biodiesel: a case study in Jambi Province of Indonesia," Int. J. Life Cycle Assess., vol. 18, no. 7, pp. 13861392, Aug. 2013.

[8] L. Chester, "Conceptualising energy security and making explicit its polysemic nature," Energy Policy, vol. 38, no. 2, pp. 887-895, Feb. 2010.

[9] P. Oosterveer, "Promoting sustainable palm oil: viewed from a global networks and flows perspective," J. Clean. Prod., vol. 107, pp. 146-153, Nov. 2015.
[10] S. Nupueng, P. Oosterveer, and A. P. J. Mol, "Implementing a palm oil-based biodiesel policy: The case of Thailand," Energy Sci. Eng., vol. 6, no. 6, pp. 643-657, Dec. 2018.

[11] S. Radhakrishnan, ; Yuvarajan Devarajan, ; Arulprakasajothi Mahalingam, and B. Nagappan, "Emissions analysis on diesel engine fueled with palm oil biodiesel and pentanol blends," $J$. Oil Palm Res., vol. 29, no. 3, pp. 380-386, 2017.

[12] M. de A. D'Agosto et al., "Comparative study of emissions from stationary engines using biodiesel made from soybean oil, palm oil and waste frying oil," Renew. Sustain. Energy Rev., vol. 70, pp. 1376-1392, Apr. 2017.

[13] C.-Y. Peng, C.-H. Lan, P.-C. Lin, and Y.-C. Kuo, "Effects of cooking method, cooking oil, and food type on aldehyde emissions in cooking oil fumes," J. Hazard. Mater., vol. 324, no. B, pp. 160-167, Feb. 2017.

[14] Y. Putrasari, A. Praptijanto, W. B. Santoso, and O. Lim, "Resources, policy, and research activities of biofuel in Indonesia: A review," Energy Reports, vol. 2, pp. 237-245, Nov. 2016

[15] S. Guo and H. Zhao, "Fuzzy best-worst multi-criteria decisionmaking method and its applications," Knowledge-Based Syst., vol. 121, pp. 23-31, Apr. 2017.

[16] K. Govindan, S. Rajendran, J. Sarkis, and P. Murugesan, "Multi criteria decision making approaches for green supplier evaluation and selection: a literature review," J. Clean. Prod., vol. 98, pp. 66-83, Jul. 2015.

[17] J. A. Alonso and M. T. Lamata, "Consistency in the analytic hierarchy process: A new approach," Int. J. Uncertainty, Fuzziness Knowlege-Based Syst., vol. 14, no. 4, pp. 445-459, Aug. 2006.

[18] F. Y. Partovi, "Determining What to Benchmark: An Analytic Hierarchy Process Approach," Int. J. Oper. Prod. Manag., vol. 14, no. 6, pp. 25-39, Jun. 1994.

[19] A. Jadhav and R. Sonar, "Analytic Hierarchy Process (AHP), Weighted Scoring Method (WSM), and Hybrid Knowledge Based System (HKBS) for software selection: A comparative study," in 2009 Second International Conference on Emerging Trends in Engineering \& Technology, 2009, pp. 991-997.

[20] A. S. Jadhav and R. M. Sonar, "Evaluating and selecting software packages: A review," Inf. Softw. Technol., vol. 51, no. 3, pp. 555-563, Mar. 2009.

[21] P. Schleifer and Y. Sun, "Emerging markets and private governance: the political economy of sustainable palm oil in China and India," Rev. Int. Polit. Econ., vol. 25, no. 2, pp. 190214, Mar. 2018.

[22] B. Shankar, N. Thaiprasert, S. Gheewala, and R. Smith, "Policies for healthy and sustainable edible oil consumption: a stakeholder analysis for Thailand," Public Health Nutr., vol. 20, no. 6, pp. 1126-1134, Apr. 2017.

[23] S. Mekhilef, S. Siga, and R. Saidur, "A review on palm oil biodiesel as a source of renewable fuel," Renew. Sustain. Energy Rev., vol. 15, no. 4, pp. 1937-1949, May 2011.

[24] J. C. Gaskell, "The role of markets, technology, and policy in generating palm-oil demand in Indonesia," Bull. Indones. Econ. Stud., vol. 51, no. 1, pp. 29-45, Jan. 2015.

[25] S. P. de Souza, S. Pacca, M. T. de Ávila, and J. L. B. Borges, "Greenhouse gas emissions and energy balance of palm oil biofuel," Renew. Energy, vol. 35, no. 11, pp. 2552-2561, Nov. 2010.

[26] D.-S. Kim, M. Hanifzadeh, and A. Kumar, "Trend of biodiesel feedstock and its impact on biodiesel emission characteristics," Environ. Prog. Sustain. Energy, vol. 37, no. 1, pp. 7-19, Jan. 2018.

[27] M. H. Rocha et al., "Life Cycle Assessment (LCA) for biofuels in Brazilian conditions: A meta-analysis," Renew. Sustain. Energy Rev., vol. 37, pp. 435-459, Sep. 2014.

[28] P. Yatim, M.-N. Mamat, S. H. Mohamad-Zailani, and S. Ramlee, "Energy policy shifts towards sustainable energy future for Malaysia," Clean Technol. Environ. Policy, vol. 18, no. 6, pp. 1685-1695, Aug. 2016. 
IPTEK Journal of Proceedings Series No. (5) (2019), ISSN (2354-6026)

The $1^{\text {st }}$ International Conference on Business and Management of Technology (IConBMT)

August 3rd 2019, Institut Teknologi Sepuluh Nopember, Surabaya, Indonesia

[29] L. Wei, C. S. Cheung, and Z. Ning, "Influence of waste cooking oil biodiesel on combustion, unregulated gaseous emissions and particulate emissions of a direct-injection diesel engine," Energy, vol. 127, pp. 175-185, May 2017.

[30] I. J. Bateman, B. Fisher, E. Fitzherbert, D. Glew, and R. Naidoo,
"Tigers, markets and palm oil: market potential for conservation," Oryx, vol. 44, no. 2, pp. 230-234, Apr. 2010.

[31] D. Khatiwada, C. Palmén, and S. Silveira, "Evaluating the palm oil demand in Indonesia: production trends, yields, and emerging issues," Biofuels, pp. 1-13, May 2018. 